Marquart, Lea, Goethes Faust in Frankreich, Studien zur dramatischen Rezeption im 19. Jahrhundert

\title{
Claude Colbus
}

\section{OpenEdition}

\section{Journals}

Édition électronique

URL : http://journals.openedition.org/ifha/2243

DOI : 10.4000/ifha.2243

ISSN : 2198-8943

\section{Éditeur}

IFRA - Institut franco-allemand (sciences historiques et sociales)

Référence électronique

Claude Colbus, « Marquart, Lea, Goethes Faust in Frankreich, Studien zur dramatischen Rezeption im 19. Jahrhundert », Revue de l'IFHA [En ligne], Date de recension, mis en ligne le 01 janvier 2010, consulté le 22 septembre 2020. URL : http://journals.openedition.org/ifha/2243 ; DOI : https://doi.org/10.4000/ ifha. 2243

Ce document a été généré automatiquement le 22 septembre 2020.

(C)IFHA 


\title{
Marquart, Lea, Goethes Faust in Frankreich, Studien zur dramatischen Rezeption im 19. Jahrhundert
}

\author{
Claude Colbus
}

Dès les premières lignes, L.M. expose clairement l'objet de son étude : «Peu d'œuvres ont influencé le monde littéraire de façon aussi importante que le Faust I de Johann Wolfgang von Goethe ; et peu d'œuvres ont à ce point passionné la recherche. Néanmoins, l'histoire de son rayonnement n'a pas été entièrement explorée. Ainsi, il n'existe pas d'exposé général de la réception de Faust en France. C'est cette lacune que se propose de combler l'ouvrage suivant. Son but : présenter la réception dramatique de la pièce goethéenne au XIXe siècle et analyser son développement sous l'angle historico-littéraire. »

Pour ce faire, l'auteur revient tout d'abord sur la présence du mythe faustien en France avant 1800, avant de consacrer un premier chapitre aux traductions du drame goethéen. À la lumière de quatre extraits choisis, L.M. tente de cerner la spécificité de chaque traduction, et de déterminer si les traducteurs ont travaillé en fonction de la langue-source, de la langue-cible ou d'un projet poétique singulier. Dans un second chapitre sont examinées les œuvres faisant montre d'une réelle appropriation du drame goethéen. L.M. distingue ainsi les adaptations, qui empruntent au Faust allemand sa structure et ses principaux personnages, les drames faisant allusion à la pièce de Goethe (par le nom de leurs protagonistes, leur schéma dramatique, etc.), et les œuvres qui tiennent sur le drame goethéen un discours métapoétique. Enfin, dans un troisième et dernier temps, l'auteur s'intéresse aux réécritures et aux adaptations musicales de Faust, en particulier celles de Berlioz et de Gounod, mais également à des œuvres moins connues, ou dans lesquelles la référence à Faust est moins marquée, comme le Faust de Louise Bertin ou La Fée aux roses d'Eugène Scribe et Henri de SaintGeorges. Les métamorphoses subies par Faust et Méphistophélès sont régulièrement mises en relief dans une perspective intertextuelle plus large, grâce à laquelle l'auteur 
donne un aperçu du rôle de la littérature anglaise dans la dynamique française de réécriture de Faust.

En conclusion, L.M., fournit un aperçu de l'évolution chronologique - et non plus par genre de texte - de la réception dramatique du Faust de Goethe en France, reprenant les points forts de chaque phase. Une bibliographie extrêmement détaillée, dans laquelle l'auteur signale de quelle bibliothèque proviennent les livres des adaptations et traductions faustiennes étudiées, complète son travail. Enfin, la majorité des textes étant difficilement accessibles, l'auteur a joint en annexe les principaux extraits des œuvres sur lesquels elle fonde ses analyses.

Outre quelques inexactitudes concernant la réception par le public des œuvres étudiées, on peut regretter que la fidélité au Faust de Goethe soit mesurée à l'aune du degré d'intertextualité, sans que ne soit réellement interrogée la fidélité à l'esprit du drame allemand. Mais on constate avec plaisir que l'auteur a su combiner à la fois interprétation des "classiques " et analyse des œuvres mineures, et offre ainsi un aperçu quasi exhaustif des œuvres françaises inspirées de Faust, sans jamais perdre de vue le cœur de sa réflexion. Une langue précise et une démarche claire, sous-tendue par une méthodologie irréprochable, facilitent l'accès à cet ouvrage qui se révèle ainsi d'une lecture très agréable, tant pour le chercheur que pour l'amateur du chef-d'œuvre de Goethe.

Claude Colbus (Université de Metz) 